\title{
HMGB1 Neutralizing Antibody Attenuates Cardiac Injury and Apoptosis Induced by Hemorrhagic Shock/Resuscitation in Rats
}

\author{
Yu Zhou, ,a,\# Yan $\mathrm{Li}^{b, \#}$ and Tong $\mathrm{Mu}^{c}$ \\ ${ }^{a}$ Department of Orthopedics, Beijing Chao-Yang Hospital, Capital Medical University; Beijing 100043, P. R. China: \\ ${ }^{b}$ Medical Examination Center, Beijing Military General Hospital; Beijing 100007, P. R. China: and ${ }^{c}$ Department of \\ Stomatology, China Meitan General Hospital; Beijing 100028, P. R. China. \\ Received January 11, 2015; accepted April 18, 2015; advance publication released online June 3, 2015
}

\begin{abstract}
High-mobility group box 1 (HMGB1) and its natural receptor, Toll-like receptor-4 (TLR4), are involved in various infectious or noninfectious diseases including hemorrhagic shock. HMGB1 neutralizing antibody (anti-HMGB1 monoclonal antibody $(\mathrm{mAb})$ ) treatment was shown to alleviate ischemia-reperfusion injury effectively. The aim of this study was to explore whether and by what mechanisms anti-HMGB1 mAb attenuates hemorrhagic shock and resuscitation (HS/R)-induced cardiac injury. Employing rat HS/R models, we found that anti-HMGB1 mAb treatment improved HS/R-induced cardiac function deterioration, attenuated cardiac enzyme elevation, improved ATP loss, and protected cardiac tissue. Anti-HMGB1 mAb also inhibited the production of inflammatory factors interleukin (IL)-1 $\beta$, IL-6, and tumor necrosis factor- $\alpha$ (TNF- $\alpha$ ). Moreover, anti-HMGB1 mAb reduced apoptotic responses by suppressing activated caspase-3 and reversing apoptotic gene expression of capase-3, Bax, and Bcl-2 in rat cardiac tissue. Moreover, anti-HMGB1 mAb decreased HS/R-induced HMGB1 and TLR4 expression elevation. We further confirmed that anti-HMGB1 mAb inhibited lipopolysaccharide-activated HGMB1 and TLR4 expression and decreased inflammatory factors IL-1 $\beta$, IL-6, and TNF- $\alpha$ at the cellular level. It was concluded that anti-HMGB1 mAb treatment protects rats from cardiac injury induced by $\mathrm{HS} / \mathrm{R}$, and the beneficial effects may be related to its inhibitory effects on the HMGB1-TLR4 axis.
\end{abstract}

Key words hemorrhagic shock; high mobility group box 1 (HMGB1); anti-HMGB1 monoclonal antibody; inflammation; apoptosis

High mobility group box 1 (HMGB1) also named as amphoterin, was found by Wang et al. in 1999.1) Later, as a late phase inflammatory mediator, HMGB1 was found to play important roles during various diseases development such as sepsis, hemorrhagic shock (HS), tumor, and others. ${ }^{2-4)}$ HMGB1 could be passively secreted by activated immune cells or passively released from necrotic cells into the extracellular milieu. The released HMGB1 mediates the response to infection and injury by binding with high affinity to several receptors including the receptor for advanced glycation end products (RAGE), and Toll-like receptors (TLR)-2 and -4, thereby promoting inflammation. ${ }^{5,6}$ TLR4 has been recognized to play a critical role in the pathogenesis of ischemia-reperfusion injury during kinds of diseases. ${ }^{7,8)}$ The important role of TLR4 during hemorrhagic shock was also demonstrated. ${ }^{9)}$ Hemorrhagic shock, a common death cause around the world, is wellknown for its intricate pathophysiological processes. Besides hypotension, hypoxemia, and the following ischemic damages involved in the development of HS, fluid resuscitation can also result in ischemia-reperfusion injury. ${ }^{10,11)}$ Hemorrhagic shock and resuscitation (HS/R)-induced damages can ultimately result in systemic inflammatory responses, or even multiple organ failure (MOF). Though the exact mechanisms of organ injury induced by $\mathrm{HS} / \mathrm{R}$ are not fully revealed, inflammation and apoptosis are considered as two potential factors. ${ }^{11)}$

Anti-HMGB1 neutralizing antibody was shown to be effectively attenuated gut barrier dysfunction and improves survival after hemorrhagic shock. ${ }^{12)}$ Oozawa et al. demonstrated that neutralizing HMGB1 effectively ameliorating ischemia-re-

\footnotetext{
${ }^{\#}$ These authors contributed equally to this work.

perfusion injury in rats. ${ }^{13,14)}$ In consideration of the protective effects of neutralizing HMGB1 method, we further explore this method on hemorrhagic shock. In the present study, we firstly elucidated the protective effects of neutralizing antiHMGB1 antibody on rat hemorrhagic shock models, and the anti-apoptosis and anti-inflammation effects of neutralizing anti-HMGB1 antibody were explored. Our study may provide new evidence for application of the neutralizing anti-HMGB1 antibody clinically.

\section{MATERIALS AND METHODS}

Chemicals and Instruments Creatine kinase $\mathrm{MB}$ isozyme (CK-MB) and lactate dehydrogenase (LDH) levels detection kits, cytoplasmic protein extraction kit, ATP assay kit, and RNA extracting kit were bought from Beyotime Inc. (Jiangsu, China). Lipopolysaccharide (LPS) was purchased from Sigma Chemical Company (St. Louis, MO, U.S.A.). PoweLab system was from AD Instruments (Colorado Springs, CO, U.S.A.). Spectrophotometer was from PowerWave XS, BioTek Inc. (Vermont, U.S.A.). Luminometer was from Berthold Inc. (Stuttgart, Germany). Anti-HMGB1, anti-active caspase-3, and anti-ED1 primary antibodies were bought from Millipore (Bedford, U.S.A.). Anti-TLR4, anti-Fas, and antiFasL antibodies were bought from Abcam (Cambridge, U.K.). Nitrocellulose filter membranes were bought from Millipore. Commercial immunohistochemistry staining kit was from ZSGB-BIO Co., Ltd. (Beijing, China). SYBR ${ }^{\circledR}$ Select Master Mix kit was from TaKaRa (Japan). Real-Time polymerase chain reaction (PCR) system was from Applied Biosystems (Foster City, CA, U.S.A.). The chemiluminescence detecting 
a $\mathrm{A}$
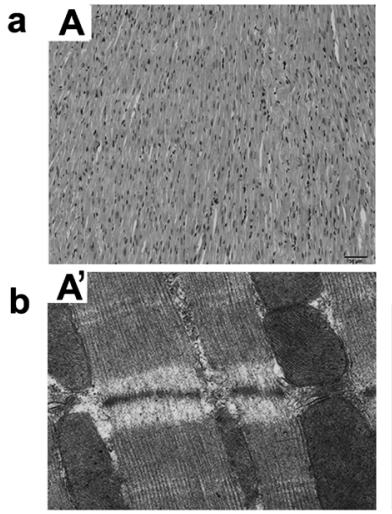

B
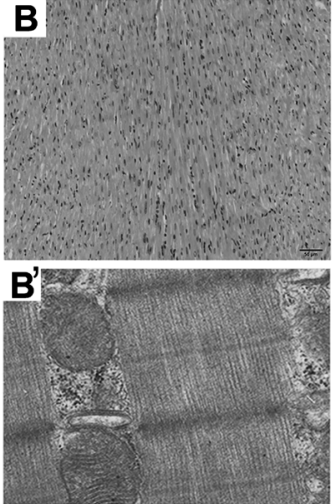
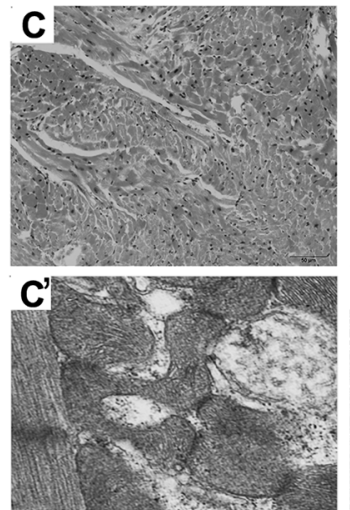
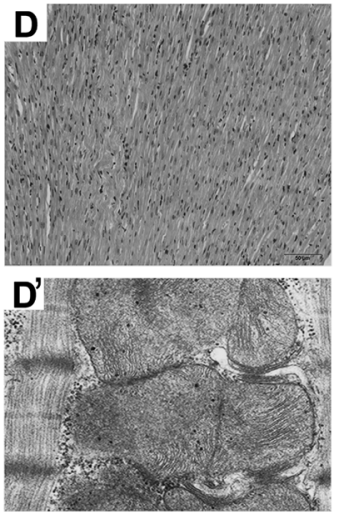

Fig. 1. Morphological Investigation on Rat Cardiac Tissue

(a) Histologic analysis of the HE staining in rat cardiac tissues, (A) Sham group, (B) IgG Control group (C) HS group (D) HS+ $\alpha$-HMGB1 group. (b) Ultrastructure analysis of transmission electron microscopy in rat cardiac tissues, $\left(\mathrm{A}^{\prime}\right)$ Sham group, $\left(\mathrm{B}^{\prime}\right)$ IgG Control group $\left(\mathrm{C}^{\prime}\right) \mathrm{HS}$ group $\left(\mathrm{D}^{\prime}\right) \mathrm{HS}+\alpha-\mathrm{HMGB} 1$ group

system was from Clinx Science Instruments Co., Ltd. (Shanghai, China). Neutralizing rabbit anti-rat HMGB1 monoclonal antibody (Cat: a026, clone: $4 . \mathrm{C}_{5} \cdot \mathrm{B}_{7}$ which recognizing the $\mathrm{C}$ terminal sequence of the HMGB1 molecule was refined) and immunoglobulin $\mathrm{G}$ ( $\mathrm{IgG}$ ) were obtained from Jingmei Biotech Engineering Co., Ltd. (Beijing, China). Active HMGB1 peptide was purchased from Abcam (Cambridge, U.K.). In situ cell death detection kit was purchased from Roche Ltd. (Basel, Switzerland). Commercial enzyme-linked immunosorbent assay (ELISA) Kits for detecting interleukin (IL)- $\beta$, IL-6, and tumor necrosis factor (TNF)- $\alpha$ were purchased from R\&D Systems Inc. (Minneapolis, MN, U.S.A.)

Animals Male Sprague-Dawley (SD) rats weighed 250-350 g were used in this study, and all the animals were received human care and in compliance with the Declaration of the National Institutes of Health Guide for Care and Use of Laboratory Animals (Publication No. 85-23, revised 1996). Animal experimental protocols and surgical procedures adopted in this study were reviewed and approved by the Animal Care and Use Committee of the Capital Medical University. All animals were allowed ad libitum access to food and water until experiments. After 1 week of acclimatization, rats were fasted overnight before the experiments and were allowed free access to water.

Testing Neutralizing Activity of the Anti-HMGB1 Antibody The neutralizing activity of the anti-HMGB1 antibody was confirmed by TNF- $\alpha$ releasing assay in active HMGB1 peptide-stimulated macrophage cultures. In brief, murine macrophage-like RAW264.7 cells were pre-treated with neutralizing antibodies $(50 \mu \mathrm{g} / \mathrm{mL})$ or control $\operatorname{IgG}(50 \mu \mathrm{g} / \mathrm{mL})$ for $1 \mathrm{~h}$ and then stimulated with active HMGB1 peptide $(10 \mu \mathrm{g} /$ $\mathrm{mL}$ ) for up to $24 \mathrm{~h}$. Culture supernatants were collected, and assayed for TNF- $\alpha$ production according to the manual instructions of the ELISA kit. The optimal concentrations of reagents in the present study were explored in our preliminary experiments (data not given).

Animal Groups and Surgical Protocol SD rats were randomly designated into 4 groups: 1) Sham-operated animals (Sham group; $n=8) ; 2$ ) Control animals treated with IgG (Control group; $n=8$ ); 3) Hemorrhagic shock animals (HS group; $n=8)$; and 4) Hemorrhagic shock animals treated with Rabbit anti-rat HMGB1 antibody $(\alpha$-HMGB1) (HS $+\alpha$-HMGB1 group; $n=8)$. The rats were anesthetized with $20 \%$ ethylurethane
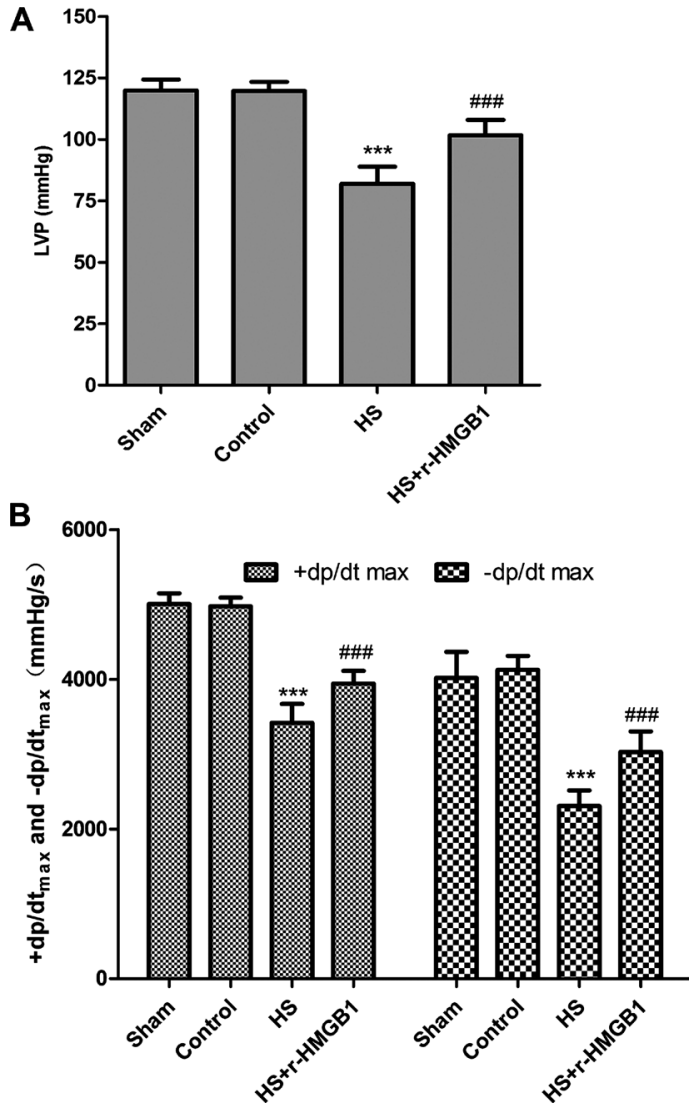

Fig. 2. Rat Cardiac Function Investigation

Rat cardiac function analyses, (A) left ventricular pressure (LVP) analysis, (B) positive and negative first derivatives of pressure $\left(+\mathrm{d} P / \mathrm{d} t_{\max }\right.$ and $\left.-\mathrm{d} P / \mathrm{d} t_{\max }\right)$ analysis, ${ }^{* * *} p<0.001, v s$. Sham and Control groups; \#\# $p<0.001$, vs. HS group.

(4 mL/kg intraperitoneally (i.p.)), and hemorrhagic shock was induced. Briefly, femoral arteries and the right femoral vein of rats were carefully separated, and a transducer which was linked by catheter between one side femoral artery and PoweLab system. Hemorrhagic shock was initiated by rapidly blood-drawing and maintaining of the mean arterial pressure to $40 \mathrm{mmHg}$ for $2 \mathrm{~h}$. A dose of IgG or $\alpha$-HMGB1 $(600 \mu \mathrm{g})$ was injected i.p. $30 \mathrm{~min}$ before resuscitation. Next, the rats were resuscitated by smoothly injecting Ringer's lactate solution in a volume equal to that of the blood drawing out through the 
A

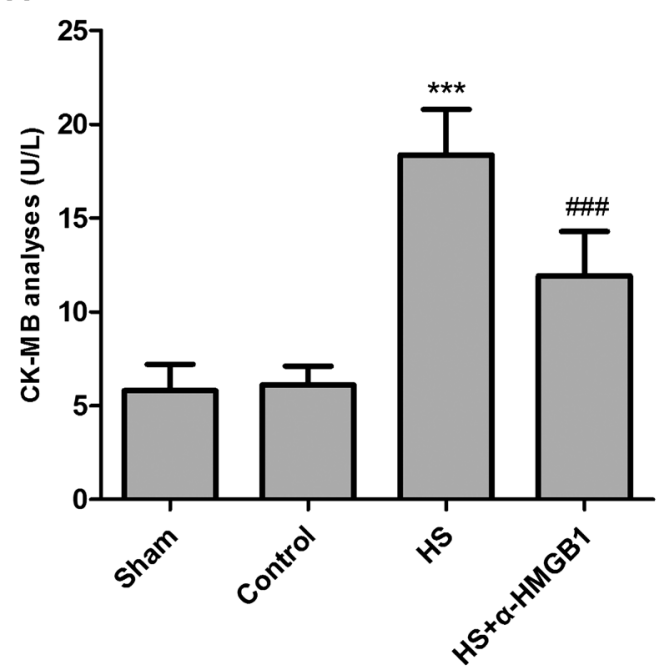

B

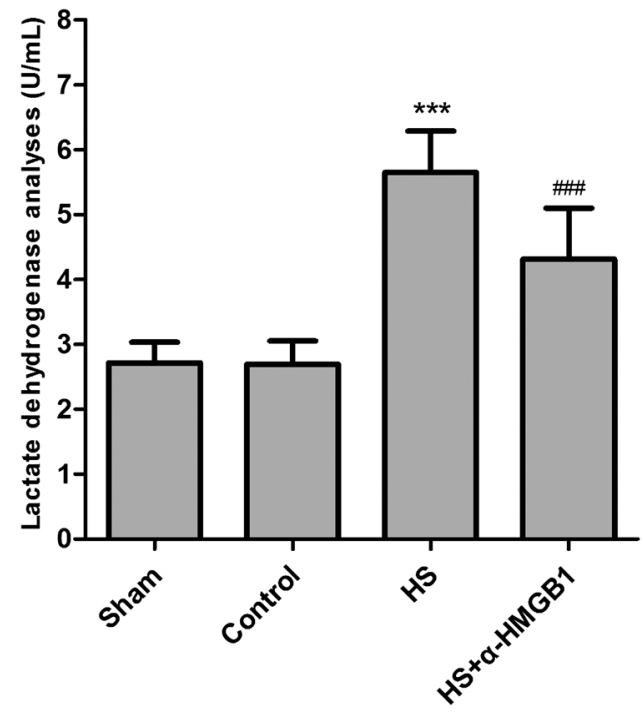

Fig. 3. Myocardial Enzymes Assays

(A) CK-MB detection, (B) LDH detection, ${ }^{* * *} p<0.001$, vs. Sham and Control groups; ${ }^{\# \#} p<0.001, v s$. HS group.

catheter pre-inserted in the right femoral vein over $60 \mathrm{~min}$. After the catheters being removed, the femoral artery was ligated, and the incisions were sutured. Hemorrhagic shock group underwent the whole surgical procedures except being injected with $0.9 \%$ sodium chloride $(\mathrm{NaCl})$ instead of the equal volume of IgG and $\alpha$-HMGB1 solution before resuscitation. In the sham-operated group, animals underwent the same surgical procedures, but neither hemorrhage nor resuscitation was performed. All catheters were removed and all wounds were sutured after resuscitation. Two hours after the end of the experimental or sham operations, animals were reanesthetized to analyze cardiac function. After hemorrhagic shock/resuscitation for $12 \mathrm{~h}$, all animals were killed by injecting overdose pentobarbital sodium after the whole procedures. Mice hearts were harvested immediately and chopped into $3 \mathrm{~mm}$ wide slices and immersed in neutral buffer $(\mathrm{pH} 7.4)$ containing $10 \%$ formalin for next experiments. Tiny pieces of cardiac tissues (wide and height $<1 \mathrm{~mm}$, length $<3 \mathrm{~mm}$ ) were obtained and fixed in 2\% glutaraldehyde for transmission electron microscopy analysis. Remained cardiac tissues were kept in a $-70^{\circ} \mathrm{C}$ freezer for later detections.

Morphological Investigation Hematoxylin and eosin (HE) staining and transmission electron microscopy were done to investigate cardiac morphological changes after hemorrhagic shock. The results of HE staining and transmission electron microscopy were analyzed by a pathological expert. All the morphological analyses were conducted in a doubleblind method.

Cardiac Function Analyses After the animals were reanesthetized, the right carotid artery was cannulated with a PE-50 catheter. The catheter was inserted into the left ventricle to monitor left ventricular pressure (LVP) and positive and negative first derivatives of pressure $\left( \pm \mathrm{d} P / \mathrm{d} t_{\max }\right)$.

Myocardial Enzymes' Assays Serum isozyme CK-MB of creatine kinase (CK), and lactate dehydrogenase (LDH) levels were detected by commercial chemical colorimetry kits according to the manufacturer's instructions. In short, the collected blood samples were stored in a $4^{\circ} \mathrm{C}$ freezer for $15 \mathrm{~min}$. The serums were obtained after the samples were centrifuged

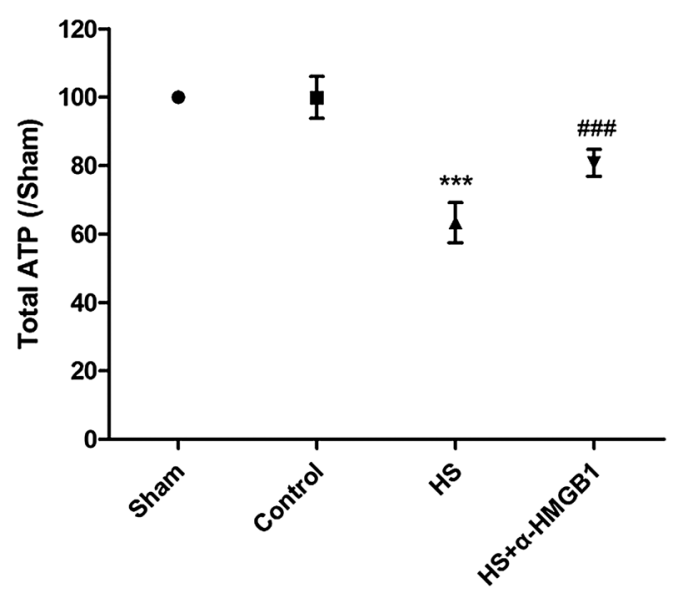

Fig. 4. Total ATP of Cardiac Tissue Analysis

The total ATP levels were expressed as ratio of RLU (/Sham group), $* * * p<0.001, v s$. Sham and Control groups; ${ }^{\# \#} p<0.001$, vs. HS group.

at $4^{\circ} \mathrm{C}$ (5000 rpm for $\left.10 \mathrm{~min}\right)$, and regents were added accordingly. Detection of optical density values were performed by a spectrophotometer at $460 \mathrm{~nm}$. The relative CK-MB and LDH levels were then calculated.

Total ATP Assays of Cardiac Tissue Total ATP assays of cardiac tissue were detected. In short, the cardiac tissues were homogenized by lysis buffer, and then were centrifuged at $4^{\circ} \mathrm{C}(12000 \mathrm{rpm}$ for $10 \mathrm{~min})$. The supernatants were collected subsequently. The ATP detecting solution was then prepared and $100 \mu \mathrm{L}$ was added into the detecting tubes. Samples of $100 \mu \mathrm{L}$ were added separately into the detecting tubes. After quickly mixing the solutions by a pipette, the RLU values were obtained by using a luminometer.

Inflammatory Cytokines Analyses Expression levels of IL-1 $\beta$, IL-6, and TNF- $\alpha$ in rats serum were determined by commercially available ELISA kits according to the manufacturer's instructions. Briefly, after the serum samples were collected, serum samples and reagents were added into assay wells in sequence, and then optical density values were read by the spectrophotometer at $450 \mathrm{~nm}$ (correction wavelength set 
at $540 \mathrm{~nm}$ ). Then the concentrations of TNF- $\alpha$, IL-6 and IL- $1 \beta$ were got accordingly.

Terminal Deoxynucleotidyltransferase-Mediated Deoxyuridine Triphosphate (dUTP) Nick-End Labeling (TUNEL) Staining In situ cell death assay was performed subsequently to detect the apoptotic cells in cardiac tissue. Briefly, the tissue sections were dewaxed and then were treated under microwave heat. The slides were incubated in Tris- $\mathrm{HCl}(0.1 \mathrm{~mol} / \mathrm{L}, \mathrm{pH} 7.5)$ solution containing $3 \%$ bovine serum albumin (BSA) and 20\% normal bovine serum for
$30 \mathrm{~min}$. For eliminating the staining of apoptotic inflammatory cells that existed in the cardiac tissue after HS/R, the slides were pre-incubated with an antibody against ED1 $(1: 200)$ overnight and then corresponding secondary antibody were added and incubated for $60 \mathrm{~min}$ at $37^{\circ} \mathrm{C}$. After being washed in phosphate buffered saline (PBS) for 3 times, the slides were covered with the TUNEL reaction mixture and were incubated for $60 \mathrm{~min}$ at $37^{\circ} \mathrm{C}$ in a dark humidified chamber. After the slides being washed three times with PBS for $5 \mathrm{~min}$ each, the apoptotic cells were counted by a pathologist under a

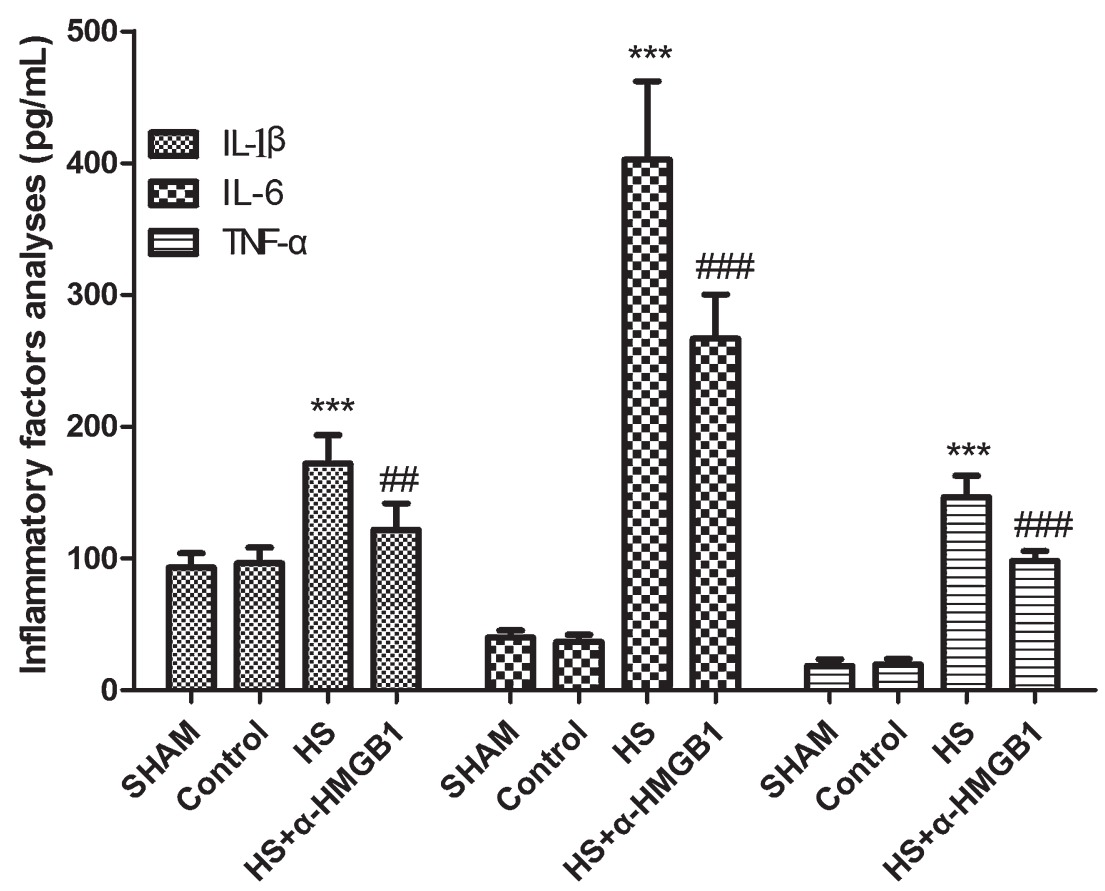

Fig. 5. Inflammatory Cytokines Analyses

${ }^{* * *} p<0.001, v s$. Sham and Control groups; ${ }^{* \# \#} p<0.001, v s$. HS group.
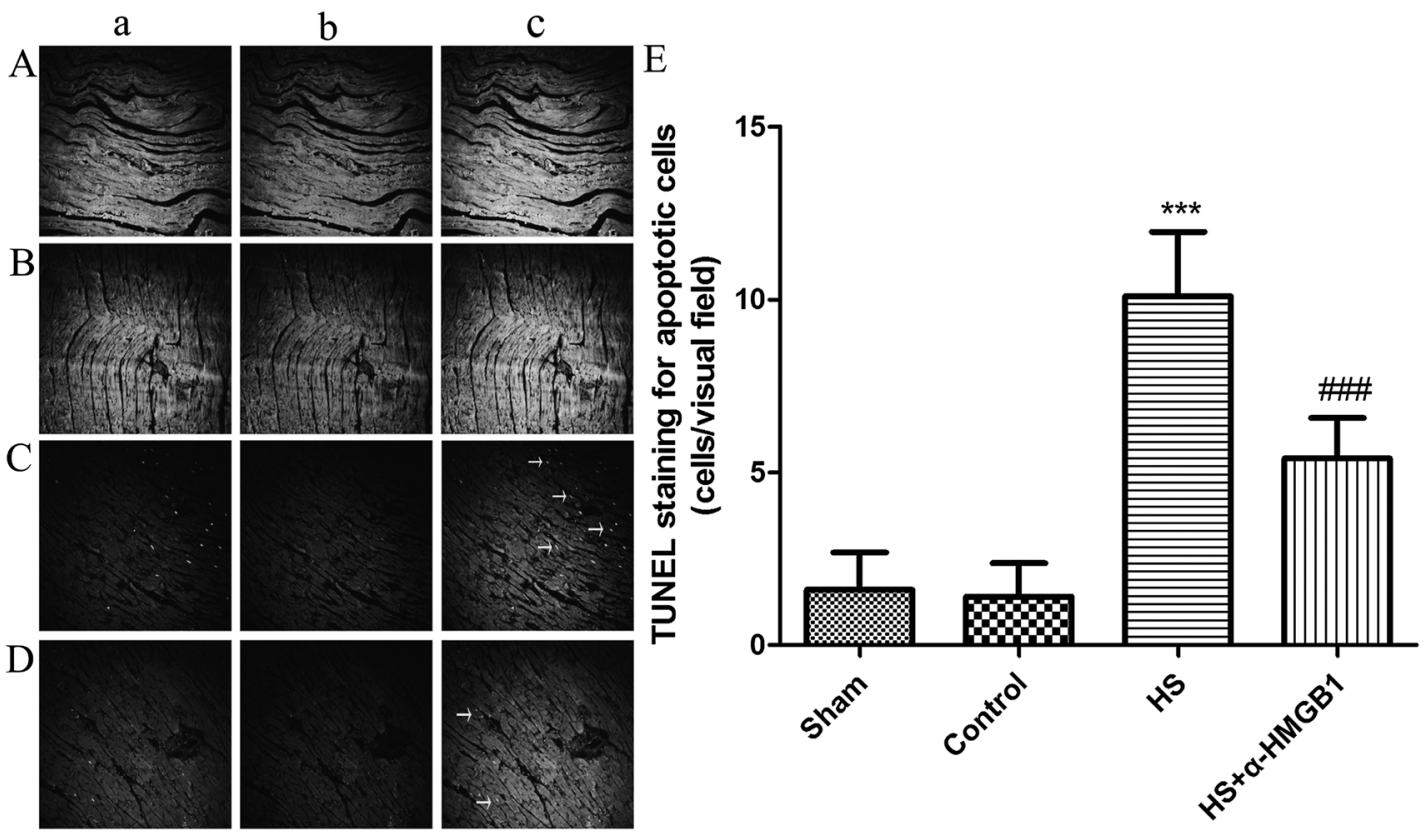

Fig. 6. TUNEL Staining on Rat Cardiac Tissue

(A) Sham group, (B) IgG Control group (C) HS group (D) HS $+\alpha$-HMGB1 group. (a) TUNEL staining, (b) ED1 staining, (c) merge, $* * * p<0.001$, vs. Sham and Control groups; ${ }^{\# \# \# ~} p<0.001$, vs. HS group. The white arrows were representing the apoptotic cells. 


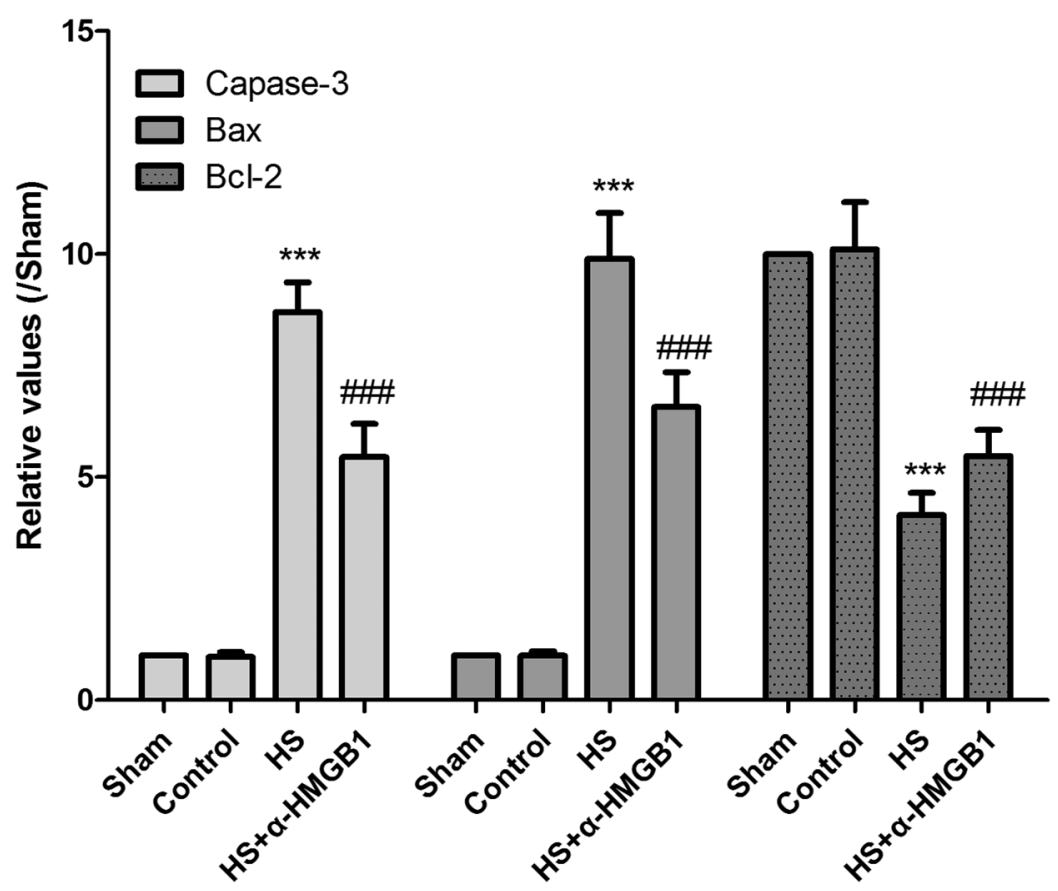

Fig. 7. Relative Expression of Bax, Bcl-2, and Caspase-3

${ }^{* * *} p<0.001$, compared to Sham and IgG Control groups; ${ }^{\# \#} p<0.001$, vs. HS group.

fluorescence microscope. The apoptotic cells in 10 consecutive visual fields were counted in each histological section using a $\times 40$ objective.

Real-Time PCR Investigation Total RNA of cardiac tissue was obtained, and real-time PCR was performed to assess mRNA expression of the following genes. The qPCR primers from Qiagen company (Germany), including Fas (Cat. No. QT00196595), Bcl-2 (Cat. No. QT00184863), Bax (Cat. No. QT01081752), 18S (Cat. No. QT00199374), and caspase-3 (Cat. No. QT01794429). Quantitative PCR was performed, and 18s was used as the housekeeping gene.

Immunohistochemistry (IHC) Assays IHC assays for Fas and FasL was performed. Briefly, the paraffin sections $\left(4 \mu \mathrm{m}\right.$ thick) were incubated under $4^{\circ} \mathrm{C}$ with primary antibodies of Fas and Fas ligand (FasL), respectively. The final reaction signal was detected. The stained sections were processed by using an image-pro plus software (version 6.0, Media Cybernetics, Inc., MD, U.S.A.). The integrated optical density (IOD) was calculated by measuring 10 consecutive visual fields for each sample using a $40 \times$ objective. All the image analyses were performed by a pathologist in a doubleblind way. Statistical analysis was applied to compare the results obtained from different experimental groups.

Western Blot Assays The extracellular levels of HMGB1 were determined by Western blot assays. In short, total protein and cytoplasmic protein of myocardial tissues were extracted. Equivalent amounts of protein $(30 \mu \mathrm{g})$ from each sample were separated on $10 \%$ sodium dodecyl sulfate (SDS)polyacrylamide gels, and then transferred onto nitrocellulose filter membranes. Then primary antibodies were incubated in a $4^{\circ} \mathrm{C}$ refrigerator overnight. The primary antibodies were anti-HMGB1, anti-active caspase-3, and anti-TLR4. The second antibodies were incubated and signals were captured.

Cell Culture and Treatment LPS is an agonist of TLR4 and macrophages are the source of cytokines. Herein, we
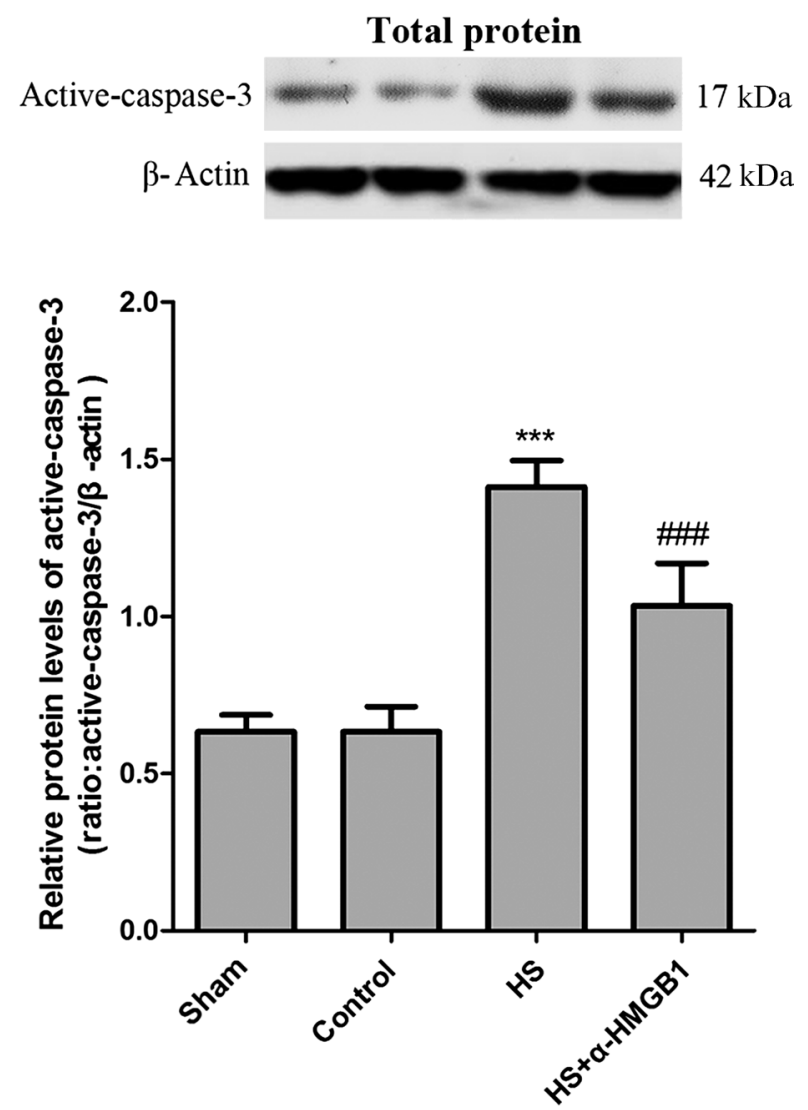

Fig. 8. Western Blot Assays of Active Caspase-3 in Rat Cardiac Tissues

Representative Western blot assays for detecting protein level of active caspase-3 in rat cardiac tissues, ${ }^{* * *} p<0.001$, vs. Sham and IgG Control groups; ${ }^{\# \# \# ~} p<0.001$, $v s$. HS group. 

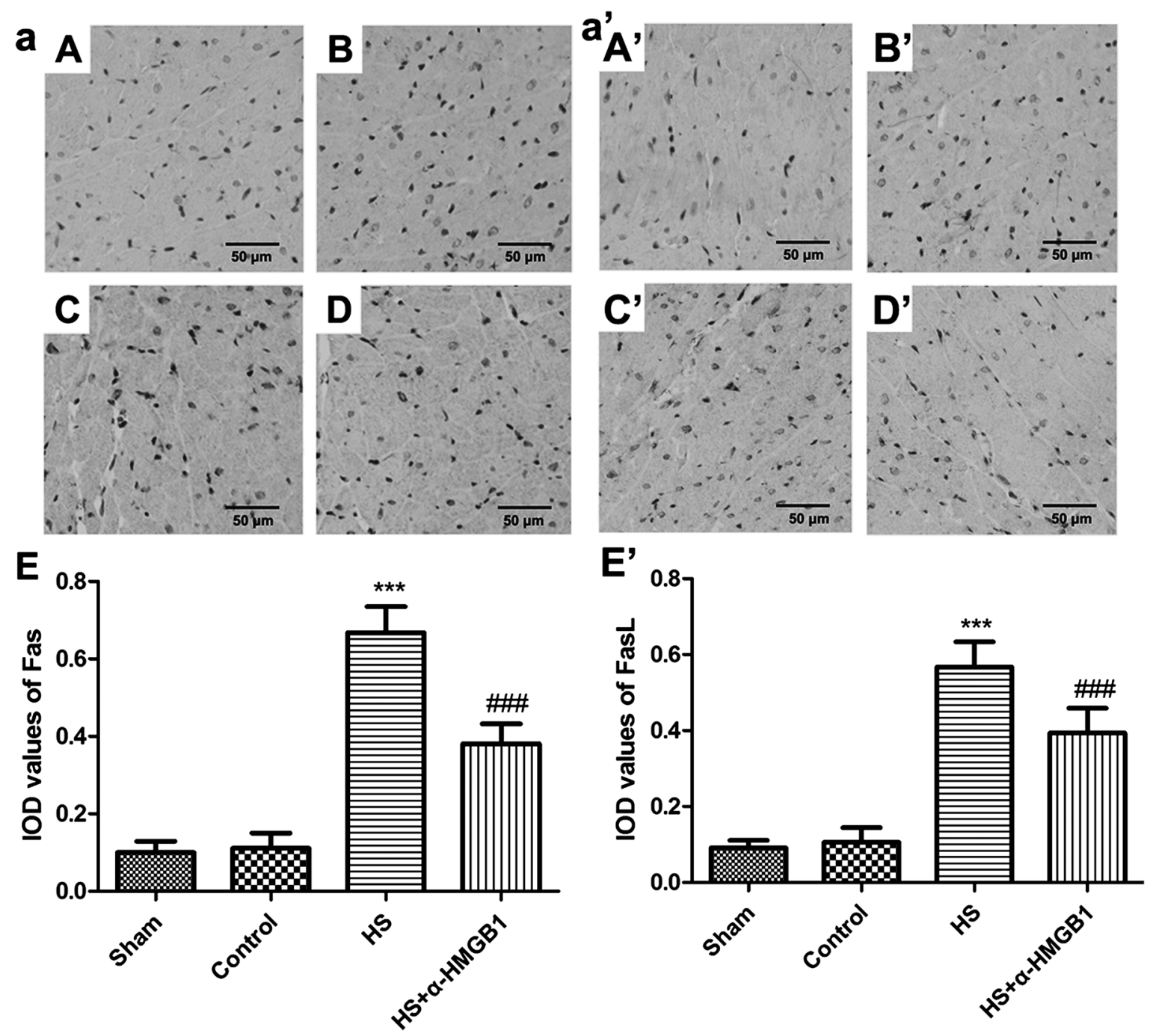

Fig. 9. Fas/FasL Expression in Rat Cardiac Tissues

(a) IHC staining of Fas and its relative expression in rat cardiac tissues, (A) Sham group, (B) IgG Control group (C) HS group (D) HS+ $\alpha$-HMGB1 group. (a') IHC staining of FasL and its relative expression in rat cardiac tissues, (A') Sham group, ( $\left.\mathrm{B}^{\prime}\right)$ IgG Control group $\left(\mathrm{C}^{\prime}\right) \mathrm{HS}$ group $\left(\mathrm{D}^{\prime}\right) \mathrm{HS}+\alpha-\mathrm{HMGB} 1 \mathrm{group}$. ${ }^{* * *} p<0.001, v s . \mathrm{Sham}$ and IgG Control groups; ${ }^{\# \#} p<0.001, v s$. HS group.

employed a macrophage cell line (RAW264.7) to observe the inhibitory effects of HMGB1 monoclonal antibody (mAb) on LPS induced inflammatory cytokines and TLR4 activation. RAW264.7 cells were grouped into IgG, $\alpha$-HMGB1, LPS, and LPS $+\alpha$-HMGB1, total 4 groups. Cells were deprived of fetal calf serum for $24 \mathrm{~h}$ and then pretreated with $\operatorname{IgG}(50 \mu \mathrm{g} /$ $\mathrm{mL})$ or $\alpha$-HMGB1 $\mathrm{mAb}(50 \mu \mathrm{g} / \mathrm{mL})$ for $30 \mathrm{~min}$. The LPS and LPS $+\alpha$-HMGB1 groups were followed by incubation with LPS $(1 \mathrm{mg} / \mathrm{mL})$ for $6 \mathrm{~h}$. The supernatant was collected to detect the contents of TNF- $\alpha$, IL- 6 , and IL- $1 \beta$ by ELISA assays. Then cells' lysate were obtained by using lysis buffer, and subsequently Western blot assays were done to test protein levels of HGMB1 and TLR4.

Statistical Analysis All values were expressed as mean \pm standard deviation (S.D.). Data were analyzed using one-way ANOVA, followed by Bonferroni post hoc multiple comparisons (GraphPad Prism for Windows version 5.01, CA, U.S.A.). Significant difference was accepted at $p<0.05$.

\section{RESULTS}

The Effects of Anti-HMGB1 Antibody on Hemorrhagic Shock Induced Cardiac Injury HE staining and transmission electron microscopy were performed to investigate the cardiac morphological changes after HS/R. Data showed that orderly-lined cardiocytes, clearly-dyed of cardiac muscle fibers, and normally-distributed intracellular spaces in rats hearts of Sham group and IgG Control group (Figs. 1A, B). However, HS/R-induced edema of myocardial cells, blurrilydyed of cardiac muscle fibers, and abnormally-distributed cardiac muscle spaces (Fig. 1C). Treatment with anti-HMGB1 antibody attenuated those changes induced by HS/R aforesaid (Fig. 1D).

As the transmission electron microscopy data showed, orderly-aligned cardiac sarcomeres, well-composed cardiac stripes, and clearly-structured mitochondria were observed in the cardiac tissue of Sham and IgG Control groups (Figs. 1 A', $\left.\mathrm{B}^{\prime}\right)$. Observations of irregularly-aligned cardiac sarcomeres, ill-formed cardiac stripes, swollen mitochondria with vaguefractured cristae, and dilated sarcoplasmic reticula were found 


\section{Cytoplasmic protein}

TLR4

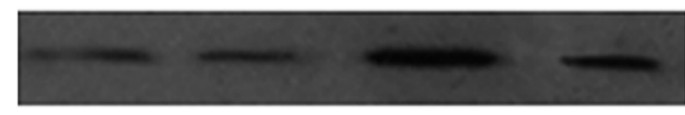

$95 \mathrm{kDa}$

HMGB1

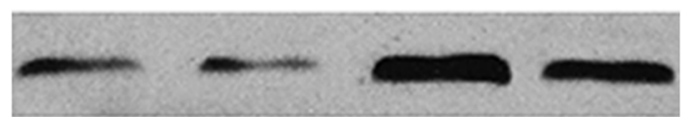

$25 \mathrm{kDa}$

\section{$\beta$-Actin}

\section{$42 \mathrm{kDa}$}
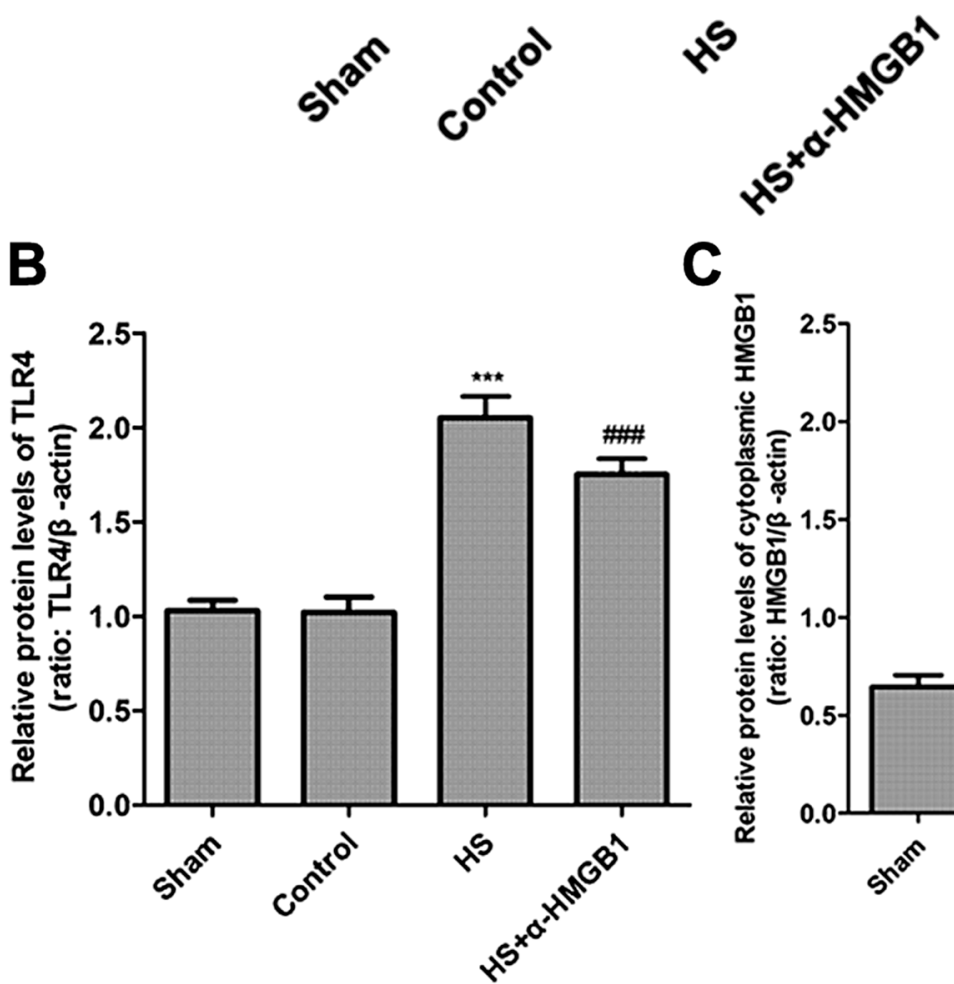

C

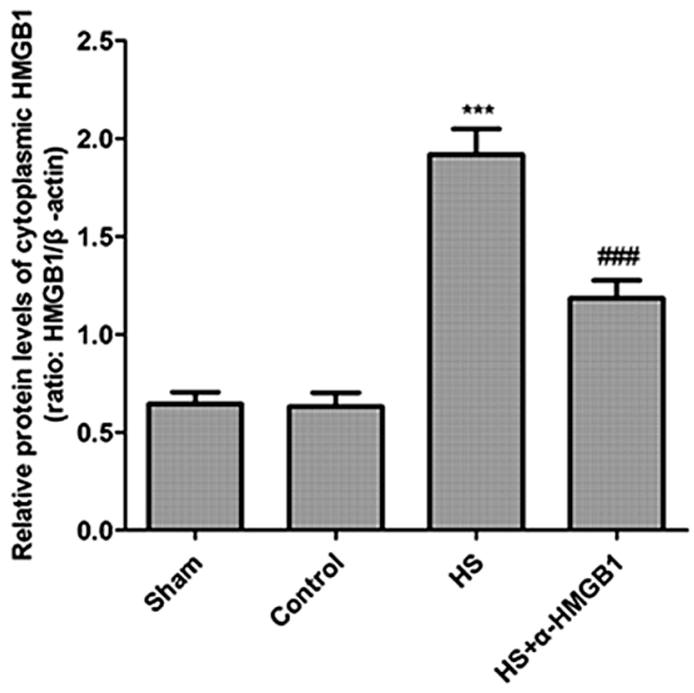

Fig. 10. Western Blot Assays of HMGB1 and TLR4 in Rat Cardiac Tissues

(A) Representative Western blot assays for detecting expression level of HMGB1 and TLR4 in rat cardiac tissues, (B) Relative expression level of TLR4 in rat cardiac tissues, (C) Relative expression level of HMGB1 in rat cardiac tissues, ${ }^{* * *} p<0.001$, vs. Sham and IgG Control groups; ${ }^{\# \#} p<0.001, v s$. HS group.

in the cardiac tissue of HS group (Fig. 1C'). In the HMGB1 treatment group, the sarcoplasmic reticula were slightly dilated and the structure of mitochondria was relatively clear and intact compared with HS group (Fig. 1D').

Treatment with Anti-HMGB1 Antibody Reversed Depression of Cardiac Function after HS/R Hemorrhagic shock and resuscitation resulted in cardiac function depression, demonstrated as LVP, $\pm \mathrm{d} P / \mathrm{d} t_{\text {max }}$ significantly dropped compared with the Sham and Control groups $(* * * p<0.001$, Fig. 2). Intraperitoneal administration of anti-HMGB1 antibody improved depression of cardiac function after $\mathrm{HS} / \mathrm{R}$. After $2 \mathrm{~h}$ of resuscitation, the HS $+\alpha-\mathrm{HMGB} 1$ group had significant improvements in LVP, $\pm \mathrm{d} P / \mathrm{d} t_{\max }$ compared with the HS groups ( ${ }^{\# \#} p<0.001$, Fig. 2).

Anti-HMGB1 Antibody Decreased Hemorrhagic Shock Induced CK-MB and LDH Levels Augment CK-MB and lactate dehydrogenase are two sensitive indexes which represented the heart damage severity. Data showed that hemorrhagic shock caused a dramatic increase of CK-MB and LDH compared with Sham and Control groups $(* * * p<0.001$, Fig. 3 ), which were markedly attenuated by anti-HMGB1 antibody treatment (\#\#\# $p<0.001$, vs. HS group, Fig. 3).

Anti-HMGB1 Antibody Treatment Alleviated HS/R-Induced Loss of Cardiac ATP The results showed that HS/R caused great loss of ATP in rat cardiac tissue $(* * * p<0.001$, vs. Sham and Control groups, Fig. 4). However, treatment with anti-HMGB1 antibody notably alleviated the loss of ATP in rat cardiac tissue ( ${ }^{\# \#} p<0.001, v s$. HS group, Fig. 4).

Anti-HMGB1 Antibody Administration Decreased HS/R-Induced Inflammatory Factors Elevation in Rats' Serum Data showed that the inflammatory factors of IL- $1 \beta$, IL-6, and TNF- $\alpha$ were all significantly increased after HS/R (Fig. 5, *** $p<0.001$, vs. Sham and Control groups, Fig. 5). Whereas, anti-HMGB1 antibody administration notably attenuated all the three inflammatory factors elevation induced by HS/R (Fig. 5, ${ }^{\# \# ~} p<0.001$, vs. HS group).

Anti-HMGB1 Antibody Administration Attenuated Apoptosis Induced by HS/R Data showed an obvious in- 

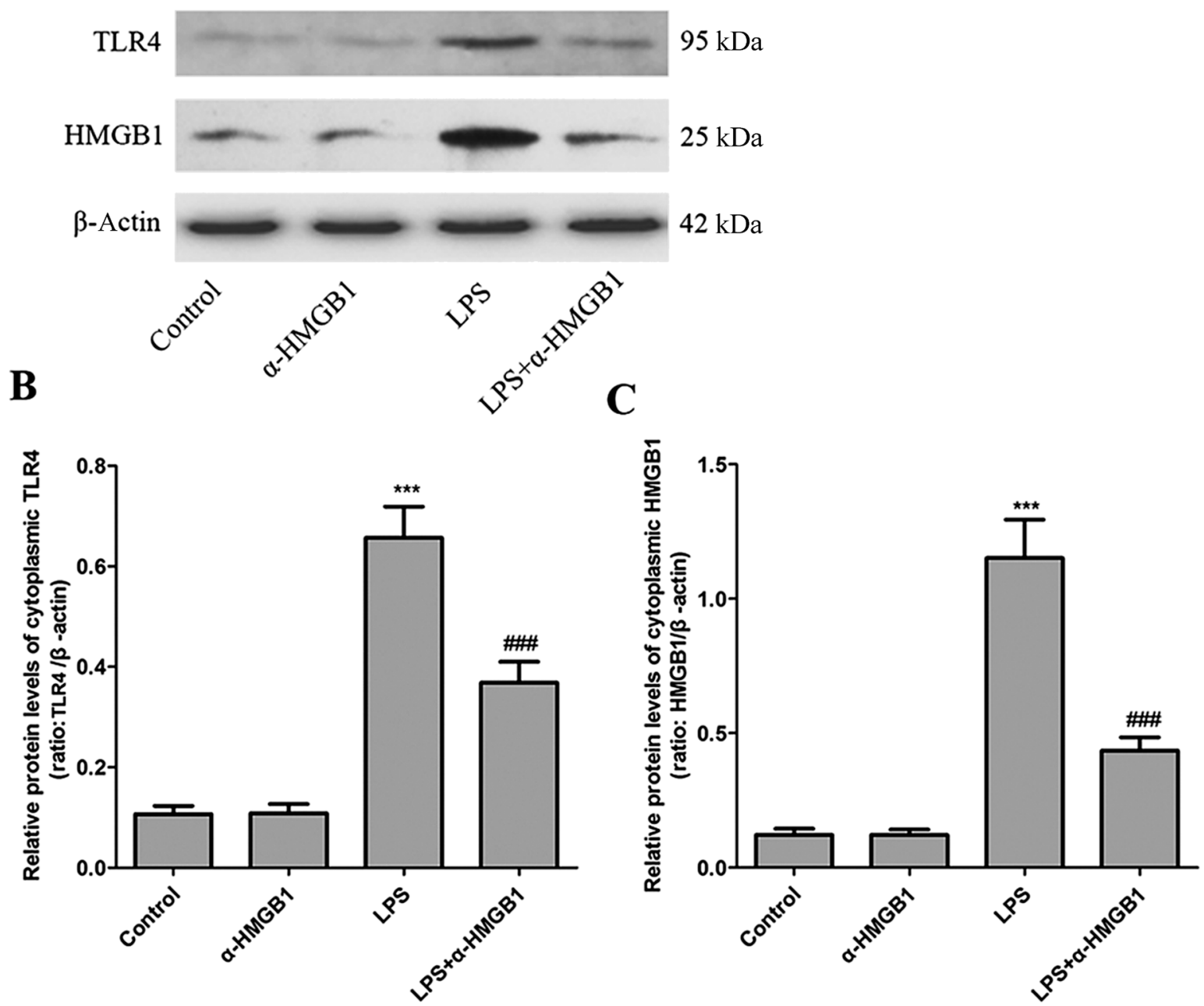

Fig. 11. Western Blot Assays of HMGB1 and TLR4 in RAW264.7 Cells

(A) Representative Western blot assays of HMGB1 and TLR4 in RAW264.7 cells, (B) Relative expression level of TLR4 in RAW 264.7 cells, (C) Relative expression level of HMGB1 in RAW264.7 cells, *** $p<0.001, v s$. Control and $\alpha$-HMGB1 groups; ${ }^{\# \#} p<0.001, v s$. LPS group.

crease in the number of apoptotic cells in the rat cardiac tissue after HS/R (Figs. 6C, E; *** $p<0.001$ vs. Sham and Control groups). In contrast, anti-HMGB1 antibody administration evidently alleviated the apoptotic response (Figs. 6D, E; \#\#\# $p<0.001$ compared with HS group), and few apoptotic cells were detected in the Sham and Control groups (Figs. 6A, B).

Effects of Anti-HMGB1 Antibody Administration on the Apoptosis-Related Factors mRNAs Levels Hemorrhagic shock and resuscitation significantly increased the mRNA levels of bax and caspase-3 (Fig. 7, *** $p<0.001$, compared to Sham and IgG Control groups). Anti-HMGB1 antibody treatment notably decreased the elevated levels of bax and caspase-3 (Fig. 7, ${ }^{\# \#} p<0.001$, vs. HS group). On the contrary, $\mathrm{HS} / \mathrm{R}$ significantly decreased the mRNA level of Bcl-2 (Fig. 7, $* * * p<0.001$, compared to Sham and IgG Control groups), and anti-HMGB1 antibody treatment obviously reversed the decreased level of Bcl-2 (Fig. 7, ${ }^{\# \#} p<0.001$, vs. HS group).

Anti-HMGB1 Antibody Administration Suppressed Activated Caspase-3 Expression Western blot assays exhibited that $\mathrm{HS} / \mathrm{R}$ resulted in great elevation expression of activated caspase- 3 in cardiac tissue in rat (Fig. 8, *** $p<0.001$, vs. Sham and $\mathrm{IgG}$ control groups). However, anti-HMGB1 antibody treatment significantly decreased the elevation of ac- tivated caspase-3 (Fig. 8, ${ }^{\# \#} p<0.001$, vs. HS group).

Effects of Anti-HMGB1 Antibody Administration Inhibited Fas/FasL Expression in Rat Cardiac Tissues IHC data showed that Fas/FasL expression in rat cardiac tissues were both obviously increased after HS/R (Fig. 9, $* * * p<0.001, v s$. Sham and IgG Control groups). However, anti-HMGB1 antibody treatment significantly decreased the elevation of both Fas and FasL (Fig. 9, ${ }^{\# \# \# ~} p<0.001$, vs. HS group).

Treatment of Anti-HMGB1 Antibody Decreased HMGB1 and TLR4 Expression in Cytoplasmic Protein of Rat Cardiac Tissue Western blot assays showed that HS/R significantly increased the expression levels of HMGB1 and TLR4 in rat cardiac cytoplasmic protein (Fig. 10, ${ }^{* * *} p<0.001$, vs. Sham and Control groups). On the other hand, antibody of HMGB1 treatment obviously decreased the elevation of protein level of HMGB1 and TLR4 in rat cardiac cytoplasm (Fig. $10,{ }^{\# \# \#} p<0.05, v s$. HS group).

Treatment of Anti-HMGB1 Antibody Decreased LPS Induced HMGB1 and TLR4 Expression in Macrophage Cells In vitro experiments showed that LPS exposure significantly increased the expression levels of HMGB1 and TLR4 in RAW264.7 cells (Fig. 11, *** $p<0.001$, vs. Control and $\alpha$-HMGB1 groups). On the other hand, antibody of HMGB1 


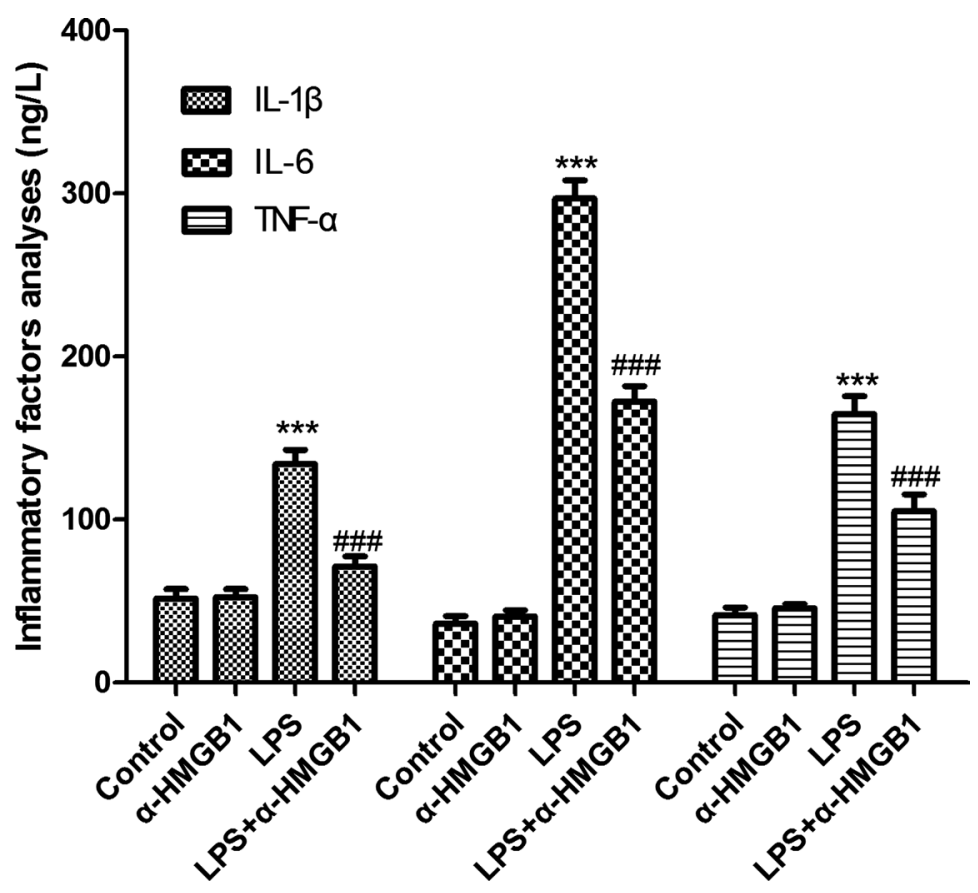

Fig. 12. Inflammatory Cytokines Analyses in RAW264.7 Cells

${ }^{* * *} p<0.001, v s$. Control and $\alpha$-HMGB1 groups; ${ }^{\# \#} p<0.001, v s$. LPS group.

treatment obviously decreased the elevation of protein level of HMGB1 and TLR4 in RAW264.7 cells (Fig. 11, ${ }^{\# \#} p<0.001$, $v s$. LPS group).

Treatment of Anti-HMGB1 Antibody Decreased LPS Induced Inflammatory Factors Expression in Macrophage Cells In vitro data also demonstrated that LPS resulted in great elevation of IL- $1 \beta$, IL- 6 , and TNF- $\alpha$ expression in RAW264.7 cells (Fig. 12, *** $p<0.001$, vs. Control and $\alpha$-HMGB1 groups). Treatment of anti-HMGB1 antibody significantly inhibited inflammatory factors IL-1 $\beta$, IL-6, and TNF- $\alpha$ expression in RAW264.7 cells (Fig. 12, ${ }^{\# \#} p<0.001, v s$. LPS group).

\section{DISCUSSION}

HMGB1, in a long time known as a late mediator during lethal disease-models of endotoxemia and sepsis, always reaches its maximal levels in the circulation at about $15-18 \mathrm{~h}$ after the initiation of inflammation responses. ${ }^{15)}$ However, a clinical study performed by Yang et al. showed that circulating HMGB1 levels are increased within $6 \mathrm{~h}$ of injury in those traumatic human victims with significant hemorrhagic shock. ${ }^{16)}$ Our study showed that protein levels of extracellular HMGB1 in rat cardiac tissue were significantly elevated after $\mathrm{HS} / \mathrm{R}$ in $6 \mathrm{~h}$, which was in accordance with those findings of Yang mentioned above.

It is sure that HMGB1 not totally answers for the inflammatory responses after HS/R. However, being released to extracellular milieu, HMGB1 could bind with its special receptor, TLR4, and exert as a central factor and prompt inflammatory responses during various pathophysiological processes. ${ }^{17,18)}$ Considering that HMGB1 plays important roles during development of inflammatory responses, researchers have tested whether HMGB1 neutralizing antibody could have beneficial effects on hemorrhagic shock. In their study, they showed that
Neutralizing HMGB1 method was also demonstrated to ameliorate gut barrier dysfunction, elevate survival, and attenuate hemorrhagic shock significantly. ${ }^{12)}$ Oozawa et al. found that HMGB1 was activated and then expand inflammation response during ischemia-reperfusion damage in rats' cardiac tissue, while treating with HGMB1 mAb effectively decreased cardiac tissue damage and infarction area. ${ }^{13)}$ Moreover, administration of HGMB1 $\mathrm{mAb}$ to neutralize the extracellular HMGB1 could protect mice renal cells from renal ischaemiareperfusion injury. ${ }^{14)}$ Recent studies reported that anti-HMGB1 $\mathrm{mAb}$ may offer a novel and potential therapy method for protecting important organs damages during various injuries. ${ }^{19,20)}$

Here, we further explored the mechanism underlying the protective effects of neutralizing anti-HMGB1 antibody method on hemorrhagic shock. We found that HS/R caused dramatic HMGB1 accumulation in cytoplasm of rat heart, together with elevation of TLR4. Also, cardiac function was significantly depressed after $\mathrm{HS} / \mathrm{R}$, shown as depression of LVP, $\pm \mathrm{d} P / \mathrm{d} t_{\max }$. Moreover, HS/R resulted in cardiac tissue injury, cardiac enzymes dramatic elevation, and notable loss of the important energetic molecule ATP. We further found that $\mathrm{HS} / \mathrm{R}$ both induced significant inflammatory and apoptotic responses, following significant elevation of both inflammatory and apoptotic factors. Additionally, we confirmed that neutralizing anti-HMGB1 antibody exerted inhibitory effects on LPS induced HMGB1 and TLR4 activation, together with attenuation of inflammatory factors elevation in RAW264.7 cells. The in vitro data demonstrated that neutralizing anti-HMGB1 antibody could exert its beneficial effects via inhibiting HMGB1/ TLR4 axis.

Inflammatory responses and apoptosis are two key links which participate and promote the progress of HS/R. Moreover, there are crosstalks between inflammation and apoptosis pathways. As an important proapoptotic factor, Fas, also is a member of the TNF-receptor superfamily, which expresses in 
various cell types. ${ }^{21,22)}$ Being activated during kinds of pathophysiological conditions, Fas will then bond with its natural ligand (FasL), next Fas/FasL will trigger the apoptotic cascade via caspases. ${ }^{23}$ The relationship between Fas/FasL and inflammation is being extensively explored, and increasing data have shown that Fas/FasL system mediates inflammation and apoptosis in kinds of diseases. ${ }^{24,25)}$ There are studies targeting Fas/FasL showed promising results in kinds of animal models. ${ }^{26,27)}$ Though there were studies showed that anti-HMGB1 mAb may offer promising therapy method during various injuries, the relationship between inflammatory responses and apoptosis pathways were seldom addressed. We found in our study that treatment with neutralizing antiHMGB1 antibody effectively decreased cytoplasmic HMGB1 and TLR4 protein accumulation. In the meantime, treatment of anti-HMGB1 antibody not only inhibited Fas/FasL expression, but also attenuated inflammatory responses. Though the exact relationship of apoptosis and inflammation during HS/R were not fully explained, our data may add new information to this field.

On the other hand, the in vitro experiments data further verified the in vivo data, showing that treatment with neutralizing anti-HMGB1 antibody inhibited inflammatory factors IL- $\beta$, IL-6, and TNF- $\alpha$ elevation, and decreased HMGB1 and TLR4 activation in macrophage cells. Thus, the present data demonstrated that anti-HMGB1 mAb treatment may suppress the HMGB1-TLR4 axis, further inhibit inflammatory responses and apoptotic pathways, and halt the progression of HS to some degree and protect HS/R-induced cardiac injury and cardiac function depression. Our study offered new information to the anti-HMGB1 $\mathrm{mAb}$ researches.

In summary, our data showed that anti-HMGB1 mAb treatment attenuated HS induced cardiac injury and cardiac function depression, inhibited inflammatory and apoptotic responses, and reversed apoptosis genes expression in rat. The beneficial effects of anti-HMGB1 mAb treatment on HS/R may be related to its inhibiting effects on HMGB1-TLR4 axis. The present study may offer new information for the neutralizing HMGB1 method application clinically.

\section{LIMITATIONS OF STUDY}

Though we showed beneficial effects of anti-HMGB1 mAb on HS/R rat models, and further showed inhibitory effects of anti-HMGB1 mAb on LPS induced HMGB1/TLR4 axis activation, the present data were still insufficient to directly link those protective effects and HMGB1-TLR4 axis.

Acknowledgment The authors thank reviewers for English language editing of the paper.

Conflict of Interest The authors declare no conflict of interest.

\section{REFERENCES}

1) Wang H, Bloom O, Zhang M, Vishnubhakat JM, Ombrellino M, Che J, Frazier A, Yang H, Ivanova S, Borovikova L, Manogue KR, Faist E, Abraham E, Andersson J, Andersson U, Molina PE, Abumrad NN, Sama A, Tracey KJ. HMG-1 as a late mediator of endotoxin lethality in mice. Science, 285, 248-251 (1999).
2) Lee CH, Yoon SJ, Lee SM. Chlorogenic acid attenuates high mobility group box 1 (HMGB1) and enhances host defense mechanisms in murine sepsis. Mol. Med., 18, 1437-1448 (2013).

3) Cai B, Deitch EA, Ulloa L. Novel insights for systemic inflammation in sepsis and hemorrhage. Mediators Inflamm., 2010, 642462 (2010).

4) Stoetzer OJ, Fersching DM, Salat C, Steinkohl O, Gabka CJ, Hamann U, Braun M, Feller AM, Heinemann V, Siegele B, Nagel D, Holdenrieder S. Circulating immunogenic cell death biomarkers HMGB1 and RAGE in breast cancer patients during neoadjuvant chemotherapy. Tumour Biol., 34, 81-90 (2013).

5) Park JS, Arcaroli J, Yum HK, Yang H, Wang H, Yang KY, Choe KH, Strassheim D, Pitts TM, Tracey KJ, Abraham E. Activation of gene expression in human neutrophils by high mobility group box 1 protein. Am. J. Physiol. Cell Physiol., 284, C870-C879 (2003).

6) Tang D, Kang R, Zeh HR 3rd, Lotze MT. High-mobility group box 1 and cancer. Biochim. Biophys. Acta, 1799, 131-140 (2010).

7) Zhao H, Perez JS, Lu K, George AJ, Ma D. Role of Toll-like receptor-4 in renal graft ischemia-reperfusion injury. Am. J. Physiol. Renal Physiol., 306, F801-F811 (2014).

8) Li XQ, Lv HW, Tan WF, Fang B, Wang H, Ma H. Role of the TLR4 pathway in blood-spinal cord barrier dysfunction during the bimodal stage after ischemia/reperfusion injury in rats. J. Neuroinflammation, 11, 62 (2014).

9) McGhan LJ, Jaroszewski DE. The role of Toll-like receptor-4 in the development of multi-organ failure following traumatic haemorrhagic shock and resuscitation. Injury, 43, 129-136 (2012).

10) Subeq YM, Peng TC, Hsu BG, Yang FL, Lee RP. Fluid resuscitation therapy application and nursing following hemorrhagic shock. Hu Li Za Zhi, 57, 17-21 (2010).

11) Angele MK, Schneider CP, Chaudry IH. Bench-to-bedside review: Latest results in hemorrhagic shock. Crit. Care, 12, 218 (2008).

12) Yang R, Harada T, Mollen KP, Prince JM, Levy RM, Englert JA, Gallowitsch-Puerta M, Yang L, Yang H, Tracey KJ, Harbrecht BG, Billiar TR, Fink MP. Anti-HMGB1 neutralizing antibody ameliorates gut barrier dysfunction and improves survival after hemorrhagic shock. Mol. Med., 12, 105-114 (2006).

13) Oozawa S, Mori S, Kanke T, Takahashi H, Liu K, Tomono Y, Asanuma M, Miyazaki I, Nishibori M, Sano S. Effects of HMGB1 on ischemia-reperfusion injury in the rat heart. Circ. J., 72, 1178-1184 (2008).

14) Li J, Gong Q, Zhong S, Wang L, Guo H, Xiang Y, Ichim TE, Wang CY, Chen S, Gong F, Chen G. Neutralization of the extracellular HMGB1 released by ischaemic damaged renal cells protects against renal ischaemia-reperfusion injury. Nephrol. Dial. Transplant., 26, 469-478 (2011).

15) Naglova H, Bucova M. HMGB1 and its physiological and pathological roles. Bratisl. Lek Listy, 113, 163-171 (2012).

16) Yang QW, Xiang J, Zhou Y, Zhong Q, Li JC. Targeting HMGB1/ TLR4 signaling as a novel approach to treatment of cerebral ischemia. Front. Biosci., 2, 1081-1091 (2010).

17) Vande Walle L, Kanneganti TD, Lamkanfi M. HMGB1 release by inflammasomes. Virulence, 2, 162-165 (2011).

18) Tsung A, Tohme S, Billiar TR. High-mobility group box-1 in sterile inflammation. J. Intern. Med., 276, 425-443 (2014).

19) Okuma Y, Liu K, Wake H, Zhang J, Maruo T, Date I, Yoshino T, Ohtsuka A, Otani N, Tomura S, Shima K, Yamamoto Y, Yamamoto H, Takahashi HK, Mori S, Nishibori M. Anti-high mobility group box-1 antibody therapy for traumatic brain injury. Ann. Neurol., 72 , 373-384 (2012).

20) Tong H, Tang Y, Chen Y, Yuan F, Liu Z, Peng N, Tang L, Su L. HMGB1 activity inhibition alleviating liver injury in heatstroke. $J$ Trauma Acute Care Surg., 74, 801-807 (2013).

21) Itoh N, Yonehara S, Ishii A, Yonehara M, Mizushima S, Sameshima M, Hase A, Seto Y, Nagata S. The polypeptide encoded by the cDNA for human cell surface antigen Fas can mediate apoptosis. 
Cell, 66, 233-243 (1991).

22) Brint E, O'Callaghan G, Houston A. Life in the Fas lane: Differential outcomes of Fas signaling. Cell. Mol. Life Sci., 70, 4085-4099 (2013).

23) Ehrenschwender M, Wajant H. The role of FasL and Fas in health and disease. Adv. Exp. Med. Biol., 647, 64-93 (2009).

24) Yu WR, Fehlings MG. Fas/FasL-mediated apoptosis and inflammation are key features of acute human spinal cord injury: Implications for translational, clinical application. Acta Neuropathol., 122, 747-761 (2011).

25) Weckbach S, Hohmann C, Denk S, Kellermann P, Huber-Lang MS, Baumann B, Wirth T, Gebhard F, Bachem M, Perl M. Apoptotic and inflammatory signaling via Fas and tumor necrosis factor receptor I contribute to the development of chest trauma-induced septic acute lung injury. J. Trauma Acute Care Surg., 74, 792-800 (2013).

26) Niu FN, Zhang X, Hu XM, Chen J, Chang LL, Li JW, Liu Z, Cao $\mathrm{W}, \mathrm{Xu} \mathrm{Y}$. Targeted mutation of Fas ligand gene attenuates brain inflammation in experimental stroke. Brain Behav. Immun., 26, 61-71 (2012).

27) Sawant DA, Tharakan B, Tobin RP, Stagg HW, Hunter FA, Newell MK, Smythe WR, Childs EW. Inhibition of Fas-Fas ligand interaction attenuates microvascular hyperpermeability following hemorrhagic shock. Shock, 39, 161-167 (2013). 